\title{
Exacerbation of akinetic seizures by atropine eye drops
}

Barry D Wright

\begin{abstract}
A case is reported where atropine sulphate eye drops increased the frequency of fits in a child suffering regular akinetic seizures. This increase was marked and observed during two separate courses of eye drops. This is discussed with reference to previous reports of central nervous toxicity after the use of topical atropine sulphate.
\end{abstract}

\section{Case report}

A 3-year-old otherwise normal blonde male infant suffered akinetic seizures. A typical seizure would involve him dropping to the ground with complete loss of tone without prodrome. He would then stand up almost immediately and carry on his activities. The attacks were infrequent happening only on a monthly basis unless the child had a fever in which case they occurred up to 10 times in 1 day. Two separate electroencephalograms at 6 month intervals (while not on medication) confirmed midline spike discharges of a nature sparsely reported in the literature. ${ }^{47}$

At the age of 18 months he attended a local eye clinic and required refraction for study of a squint. He received $1 \%$ atropine sulphate drops one drop in each eye twice daily for 4 days. At this time he had up to 30 seizures per day for 5 days and these tailed off some 2 days after the course of drops had finished. The association with atropine at this time was thought to be coincidental.

At the age of 2 years and 6 months he once again received atropine sulphate $1 \%$ eye drops prior to refraction studies. Once again this was one drop in each eye twice daily for 4 days. Because of the previous association a much closer record was kept of events.

Twenty four hours after starting the eye drops he began to have an increase in seizures. Prior to the eye drops these had occurred on only two occasions in a 3 month period. After the eye drops had been started he was recorded as having $4,22,30,25,8,2$, and 1 fit on respective days. These were all akinetic seizures from which he recovered immediately. On subsequent days there was a return to the original pattern of seizures. There were no fevers or other illnesses at this time. It was noted that his pupils were dilated until the beginning of day 7 after starting the eye drops (that is 3 days after the drops were

On a subsequent occasion when he required further refraction studies atropine was avoided. Cyclopentolate was used on a once only basis and resulted in no increase in seizures.

Discussion

After administration of eye drops absorption finished).

takes place through the conjunctiva and then after passage down the lacrimal system through the nasal mucosa, pharynx, and gastrointestinal tract. To limit this many centres use ointment rather than drops for children although there are still some centres (as in the clinic attended by this child) routinely using drops.

Serious side effects of topical atropine involving the central nervous system have been reported in the medical literature on many occasions. ${ }^{128-23}$ Convulsions in association with topical atropine drops have only been reported to the Committee on Safety of Medicines through the yellow card system on one occasion since $1963,{ }^{24}$ but the literature suggests that they occur more frequently. As early as 1902 without reference to cases Rockcliffe ${ }^{25}$ suggested that convulsions were 'not infrequently seen' with atropine eye drops and more recently Davidson has referred to the association 'particularly in children'. ${ }^{3}$ Several case reports highlight the association usually in the context of wider central nervous toxicity. ${ }^{18-11}$ None of these relate to exacerbation of existing epilepsy.

The frequent central spikes found on EEG in the child in this report mostly occurred without clinical correlation. Some animal studies have shown that the EEG can be affected by atropine. Large amplitude spikes may be produced ${ }^{26}$ and the amplitude of existing spikes may be increased by up to $70 \% .{ }^{27}$ This would provide one model for an increase in the number of seizures suffered in this case. Atropine eye ointment would be expected to produce lower systemic concentrations of atropine than with eye drops and thus less likelihood of systemic reaction ${ }^{3}$ and central nervous toxicity.

1 Heath WE. Death from atropine poisoning. $\mathrm{Br} M e d$ f $1950 ; 2$ : 608.

Hoefnagel D. Toxic effects of atropine and homatropine eye drops in children. N Engl F Med 1961; 264: 168.

3 Davidson SI. Systemic effects of eye drops Trans Ophthalmol Soc UK 1974; $94: 487-95$.

4 Pedley TA, Tharp BR, Herman K. Clinical and electroencephalographic characteristics of midline parasgittal foci. Ann Neurol 1981; 9: 142-9.

5 Ehle A, Schenley CO, Jones MG. Clinical correlates of midline spikes, and analysis of 21 patients. Arch Neurol 1981; 38 : 355-7.

6 Nelson KR, Brenner RR, De La Paz D. Midline spikes: EEG and clinical features. Arch Neurol 1983; 40: 473-6.

7 Pourmand AP, Markand ON, Thomas CG. Midline spike discharges: clinical and EEG correlates. Clin Electroencephalogr 1984; 15: 232-6.

8 Morton HG, Durham NC. Atropine intoxication: its manifestations in infants and young children. 7 Pediatr $1939 ; 14$

9 Scally $\mathrm{CM}$. Poisoning after one instillation of atropine drops. BrMed F 1936; 1: 311.

10 Matthews Owens $S$. Notes on two cases of atropine poisoning. Lancet 1890 ; ii: 443 .

$11 \mathrm{Wise} \mathrm{CH}$. Case of poisoning from atropine eye drops. Br Med $\mathrm{f}$ 1904; 1: 189.

12 Baker J, Farley JD. Toxic psychosis following atropine eye drops. Br Med f 1958; 2: 1390-2

13 Hopkins F, Robyns-Jones J. Psychosis associated with atropine administration. $\mathrm{Br}$ Med F 1937; $1: 663$

14 Kelynack TN. Atropine poisoning by absorption from the conjunctiva. BrMed $\mathcal{F} 1890 ; 1: 421$. 
16 Tyson WJ. Toxic effects of atropine drops. Br Med F 1889; 2:

17 O'Connor PS, Mumma JV. Atropine toxicity. Am f Ophthalmol 1985; 99: 613-4.

18 Harel L, Frydman M. Prolonged parasympathetic paralysis and psychosis caused by atropine eye drops. F Ped Ophthalmol Strabismus 1985; 22: 38-9.

19 Duggan PJ. Mental disturbance following atropine administration. Br Med f 1937; 1: 918 .

20 Belz $\mathrm{F}$. Intoxication of a child from atropine in collyrium. Bull Soc Ophtalmol Fr 1949; 1: 853.

21 Melivier VM. A case of atropine poisoning Lancet 1935; ii: 1232.
22 Nadal J, De La Fuente V, Abadas M, Torrent J, Janie F. Toxic coma induced by anticholinergic eye drops. $\mathrm{Br} \mathrm{Med} \mathcal{F} 1987$ 295: 1352.

23 Hughes CA. Poisoning from use of atropine eye ointment $1 \%$. Trans Ophthalmol Soc UK 1938; 58: 444-6.

24 Committee on Safety of Medicines. Personal communication. 25 Rockcliffe WC. Notes on a death supposed to be from atropine eye drops to the eye. Trans Ophthalmol Soc UK 1902; 22:

26 Daniels JC, Spehlmann R. The convulsant effect of topically applied atropine. Electroenceph $\mathcal{E}$ Clin Neurophys 1973; 34:

27 Buzsaki G. Hippocampal sharp waves: their origin and significance. Brain Res 1986; 398: 242-52. 